\title{
ORIGEM, FUNCIONAMENTO E IMPORTÂNCIA DO PROCESSO DE RECONHECIMENTO, VALIDAÇÃO E CERTIFICAÇÃO DE COMPETÊNCIAS
}

\author{
ORIGIN, FUNCTIONING AND IMPORTANCE OF THE RECOGNITION, \\ VALIDATION AND CERTIFICATION OF SKILLS PROCESS
}

Viviana Silva Ferreira ${ }^{1}$

\begin{abstract}
Resumo
O processo de Reconhecimento, Validação e Certificação de Competências (RVCC), também designado por Reconhecimento de Adquiridos é cada vez mais mencionado quando o objetivo é a valorização de saberes adquiridos informalmente ao longo da vida. Este artigo pretende apresentar o processo de RVCC e refletir sobre a sua importância para a valorização pessoal e profissional dos cidadãos, das empresas, da sociedade e do país na sua generalidade. Expõe este processo tendo em conta a contextualização da realidade portuguesa e tendo por base uma revisão de literatura de vários livros, artigos e normas legisladoras.
\end{abstract}

Palavras-Chave: Reconhecimento; Formação profissional; Lifelong Learning; Validação;Certificação de Competências;

\begin{abstract}
The Recognition, Validation and Certification of Skills process (RVCC), also known as Acquired Recognition, is increasingly mentioned when the objective is to value the knowledge acquired informally throughout life. This article intends to present the RVCC process and to reflect on its importance for the personal and professional valuation of citizens, companies, society and the country. It exposes this process considering the contextualization of the Portuguese reality and based on a literature review of several books, articles and legislations.
\end{abstract}

Keywords: Recognition, Validation and Certification of Skills; Professional Training; Lifelong Learning.

\footnotetext{
${ }^{1}$ Mestre em Gestão da Formação e Administração Educacional pela Faculdade de Psicologia e de Ciências da Educação da Universidade de Coimbra (FPCEUC). Aveiro, Portugal. E-mail: vferreira2093@gmail.com
} 


\section{Introdução}

Atualmente, vive-se na Sociedade do Conhecimento onde o valor da aprendizagem é acentuado, a economia é baseada no conhecimento e o acesso à informação é constante. Aprende-se nos diversos contextos da vida, quer eles sejam formais, não formais, informais ou acidentais e o desenvolvimento de competências depende de fatores como crenças, contextos de aprendizagem, mentalidade aprendente, abertura empresarial e, acima de tudo, políticas públicas que apoiem e protejam a educação e a formação (STIGLITZ \& GREENWALD, 2016).

O desenvolvimento de novas competências possibilita a supressão de necessidades sociais e laborais (HARGREAVES, 2003), tornando-se clara a necessidade da qualificação de trabalhadores numa perspetiva Lifelong Learning ${ }^{2}$ para que acompanhem as constantes mudanças do mercado de trabalho. O processo de RVCC apresenta-se como uma resposta a esta realidade, enfatizando o que a vida ensina pessoal e profissionalmente.

Esta realidade obriga a um esforço permanente de predisposição para aprender e para trocar experiências ao longo da vida, demonstrando a importância da educação de adultos na resposta a desafios contemporâneos. A educação não pode ficar confinada à escola devendo contemplar a educação na sua totalidade e multidimensionalidade, abarcar orientação e acompanhamento, igualdade de oportunidades, autoformação, autonomia e acessibilidade.

Em Portugal "a formação surgiu no pensamento educativo bastante tarde associada redutoramente à formação profissional, como uma forma inferior de educação" (Pineau, 2000, p. 128). Em 1997 surgiu a Agência Nacional de Educação e Formação de Adultos (ANEFA) pelo Decreto-Lei n. ${ }^{o} 387 / 99$ de 28 de setembro, com competências relacionadas com a promoção de programas e projetos, o apoio a iniciativas da sociedade civil e a construção de um sistema de reconhecimento e validação das aprendizagens informais dos adultos (PORTUGAL, 1999).

\section{Origem}

\footnotetext{
${ }^{2}$ Neste artigo usar-se-á o termo Lifelong Learning, que permite a abrangência do processo de RVCC, pois é inclusivo da aprendizagem formal, informal e não formal, baseado no modelo da competência que se foca no indivíduo e nas suas competências. Em detrimento do termo Lifelong Education que exclui qualquer aprendizagem não formal e informal, baseado no modelo da qualificação, focado no posto de trabalho, onde a obtenção de um diploma significava a apetência para a execução de um certo cargo, a detenção de saberes-fazer específicos de uma profissão (BARROS, 2012).
} 
Internacionalmente, foi nos Estados Unidos da América que o processo de reconhecimento de adquiridos surgiu. Estavam no pós-guerra, quando os seus militares, por terem servido o país, estarem afastados do mercado de trabalho e quererem a reinserção social e profissional, decidiram pedir o reconhecimento das experiências adquiridas na situação militar (MATIAS, 2012).

O primeiro país a implementar o processo de RVCC foi o Canadá (1970), seguindo-se países como a França, a Austrália, a Espanha, a Alemanha e por fim Portugal (2000) com os Centros RVCC (CRVCC) criados pela ANEFA. Cada um destes países implementou o processo de acordo com a forma como queriam compor a Educação e Formação de Adultos (EFA) (cf. MATIAS, 2012, pp. 76 -78).

Em 2001, a Portaria n. ${ }^{\circ}$ 1082-A/2001 de 21 de setembro, legitimou a criação de uma rede nacional de CRVCC, que atuava segundo eixos de reconhecimento, de validação e de certificação de competências (PORTUGAL, 2001).

Esta rede, de acordo com os objetivos do Governo, passou por várias designações ao longo dos anos. De CRVCC, organizados pela ANEFA, a Centros Novas Oportunidades (CNO), coordenados, monitorizados e avaliados pela Agência Nacional para a Qualificação (ANQ), a Centros para a Qualificação e o Ensino Profissional (CQEP), coordenados pela Agência Nacional para a Qualificação e o Ensino Profissional (ANQEP), aos em 2019 designados, Centros Qualifica.

Os Centros Qualifica, deveriam retomar como foco central a qualificação de adultos assente na complementaridade entre os processos de RVCC e a obrigatoriedade de frequência de formação certificada, em função dos perfis e das necessidades individuais dos candidatos. Estes Centros constituem uma das principais estruturas que asseguram o funcionamento do Serviço Nacional de Qualificações e desenvolvem o Programa Qualifica que aposta em "percursos de formação que conduzam a uma qualificação efetiva, por oposição a uma formação avulsa, com fraco valor acrescentado do ponto de vista da qualificação e da melhoria da empregabilidade dos adultos" (PORTUGAL, 2016, p. 3006). Este Programa efetivou o Sistema de Créditos do Ensino e Formação Profissionais e o Passaporte Qualifica.

Os destinatários das atividades de um Centro Qualifica são adultos com idade igual ou superior a 18 anos, que pretendam dar continuidade ao percurso de qualificação ou que procurem potenciar a sua empregabilidade; e jovens 


\section{ISSN 2359-82}

enquadrados pela medida Garantia Jovem, entre os 15 e os 29 anos, que não se encontrem a frequentar modalidades de educação ou de formação e que não estejam inseridos no mercado de trabalho (IEFP, 2018, p.4).

Também podem frequentar estes Centros, adultos reformados, em casos devidamente fundamentados, pessoas com deficiências e incapacidades e pessoas em situação de sem abrigo acesso prioritário (IEFP, 2018).

Os Centros Qualifica consideram a formação de adultos e o reconhecimento de adquiridos fundamentais para a valorização humana no mundo laboral, e por isso permitem a certificação escolar e/ou profissional sem custos, assentando a sua intervenção nas etapas apresentadas na Figura 1.

Figura 1 - Esquema de etapas de intervenção dos Centros Qualifica

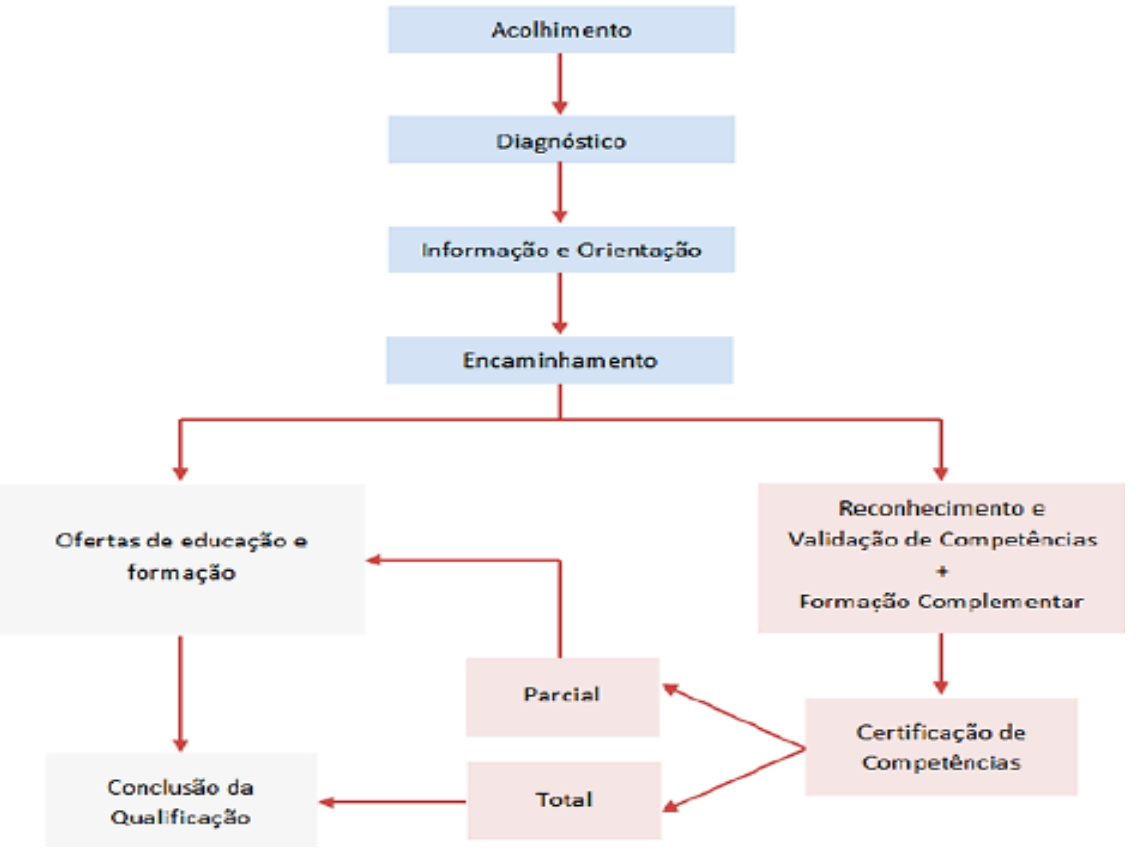

Fonte: ANQEP, 2017c, p. 6

\section{Funcionamento}

O processo de RVCC segue os princípios e valores “do desenvolvimento pessoal, da coesão e do reforço da participação social e do aprofundamento da cidadania” (RODRIGUES E ARAGÃO \& LIMA DE OLIVEIRA, 2011, p. 114), e o pensamento de John Dewey que considerava as oportunidades do quotidiano e as experiências de vida, matérias-primas da educação de adultos (NOGUEIRA, 2004). 
Não são as experiências que são reconhecidas e validadas mas as competências e aprendizagens delas obtidas, pois para que a experiência se "transforme" em aprendizagem necessita de ser refletida, consciencializada e reconstruída, confrontando-se com a realidade e contribuindo para a transformação identitária da pessoa e da sua relação com o mundo (OLIVEIRA PIRES, 2007). As competências não surgem sem ações concretas, contextos e procedimentos específicos (CAVACO, 2007).

Grande parte da aprendizagem ocorre dentro das empresas, no exercício de funções, levando a que após vários anos de experiência no exercício de uma função/profissão, as pessoas sejam detentoras de saberes e competências ${ }^{3}$ que lhes possibilitam trabalhar com eficiência e eficácia, sem qualquer comprovativo formal (STIGLITZ \& GREENWALD, 2016).

$\mathrm{O}$ processo de RVCC responde a esta realidade, tendo como objetivos proporcionar o acesso a níveis mais elevados de escolaridade/de qualificação a quem não teve oportunidade de estudar, mas tem experiência profissional, e promover as práticas de aprendizagem ao longo da vida, de responsabilidade e de valorização social do conhecimento.

Os candidatos têm a possibilidade de, concomitantemente, completarem um nível de escolaridade e adquirirem uma certificação profissional numa área específica do seu interesse. Podem obter certificação escolar, profissional ou dupla através de um processo individualizado que não tem duração definida, pois depende do número de candidatos, do seu ritmo, da sua disponibilidade e da de toda a equipa técnico-pedagógica (PORTUGAL, 2016, RODRIGUES E ARAGÃO \& LIMA DE OLIVEIRA, 2011).

\subsection{Condições de Acesso}

As condições de acesso ao processo de RVCC, para além das já mencionadas para os Centros Qualifica, e da necessidade de ter candidatos proativos, estão divididas de acordo com a certificação pretendida.

No processo de RVCC Escolar não é exigida escolaridade mínima, pois é dada aos candidatos a possibilidade de obterem certificação de nível B1 - correspondente ao $4 .^{\circ}$ ano de escolaridade -, de nível B2 - correspondente ao 6. ${ }^{\circ}$ ano de escolaridade e ao nível 1 do Quadro

\footnotetext{
${ }^{3}$ Nos processos de RVCC a definição de competência usada é a do Decreto-Lei no 396/2007 de 31 de dezembro, que a explica como a "capacidade reconhecida de mobilizar os conhecimentos, as aptidões e as atitudes em contexto de trabalho, desenvolvimento profissional, educação e desenvolvimento pessoal" (PORTUGAL, 2007, Art. ${ }^{\circ}$, alínea b, p. 9168).
} 
Nacional de Qualificações (QNQ) ${ }^{4}$-, de nível B3 - correspondente ao 9. ${ }^{\circ}$ ano de escolaridade e ao nível 2 do QNQ - ou de nível secundário - correspondente ao $12 .^{\circ}$ ano de escolaridade e ao nível 3 do QNQ.

O candidato não pode integrar um processo de RVCC que lhe confira escolaridade igual ou inferior àquela que já possui, contudo pode propor-se a um nível de certificação muito superior desde que o seu perfil se mostre adequado a tal. Esta proposta pode ser ajustada ao longo da fase de reconhecimento de competências, para um nível posterior ou prévio (ANQEP, 2017c). É necessário ter o perfil adequado, que se verifica na capacidade do candidato refletir e analisar as suas experiências de vida, valorizando as que lhe proporcionaram competências e conhecimentos que podem ser transferidos para contextos diversos.

No processo de RVCC Profissional é necessário que o candidato demonstre ter experiência profissional relevante e perfil compatível com a saída profissional à qual se candidata. Tem-se em conta as funções já desempenhadas profissionalmente, o nível de qualificação, a adequação ao processo de RVCC, a situação face ao emprego e os fatores apresentados pela ANQEP. Estes fatores (cf. ANQEP, 2017c, p.16), permitem perceber se os candidatos têm ou não capacidade de aumentarem as suas qualificações e relacionam-se com conhecimentos em áreas como matemática, tecnologias da informação e da comunicação, língua estrangeira; com aptidões como definir objetivos pessoais e profissionais, compreender e relacionar diferentes temas; e com atitudes como demonstrar iniciativa e autonomia, e compreender e aceitar as ideias/opiniões dos outros. Se o candidato tiver entre 18 e 23 anos, deve ter experiência de trabalho (na área à qual se candidata) mínima de 3 anos, comprovada pela Segurança Social (ANQEP, 2017d).

Para um processo de RVCC de Dupla Certificação as condições de acesso resultam da aglomeração das dos processos de RVCC anteriormente mencionados.

\subsection{Equipa Técnico-Pedagógica}

Para que os processos de RVCC se possam desenvolver, os Centros Qualifica contam com um Coordenador, vários Formadores e Técnicos de Orientação, RVCC (TORVCC).

\footnotetext{
${ }^{4} \mathrm{O}$ QNQ descreve as qualificações nacionais em termos de resultados de aprendizagem, de acordo com os descritores associados a cada nível de qualificação (PORTUGAL, 2009).
} 
O Coordenador representa institucionalmente os Centros e garante a sua gestão pedagógica, organizacional e financeira.

Os Formadores asseguram a formação complementar necessária aos candidatos e reconhecem as suas competências-chave, estando sempre que possível, presentes nas etapas de diagnóstico, orientação e encaminhamento para ajudarem a identificar o nível/saída profissional ao qual o candidato se deve candidatar.

Os TORVCC são responsáveis pela condução geral dos processos de RVCC (IEFP, 2018). Estes Técnicos são os motivadores dos candidatos e "animadores" das sessões, devendo criar ambientes propícios ao surgimento das memórias úteis ao processo, conquistando a confiança dos candidatos e mantendo-se neutros.

\subsection{Portefólio Reflexivo de Aprendizagens (PRA)}

O PRA é um documento pessoal, usado como base do processo de RVCC, que integra componentes reflexivas e críticas associadas a evidencias e relatos pessoais do candidato (AMADO \& FERREIRA, 2014).

No desenvolvimento do PRA os candidatos evidenciam a tomada de consciência da sua história de vida explicitando e organizando as evidências das competências adquiridas, agregando o relato biográfico, a reflexão, as pesquisas sobre algumas temáticas orientadas pelos TORVCC e o trajeto académico e profissional percorrido até ao momento (vd. Figura 2). Do PRA podem fazer parte documentos pessoais, atividades desenvolvidas ao longo do processo de RVCC e o registo do acompanhamento da equipa técnico-pedagógica (ANQEP, 2017c).

Figura 2 - Abordagem autobiográfica nos processos de RVCC 


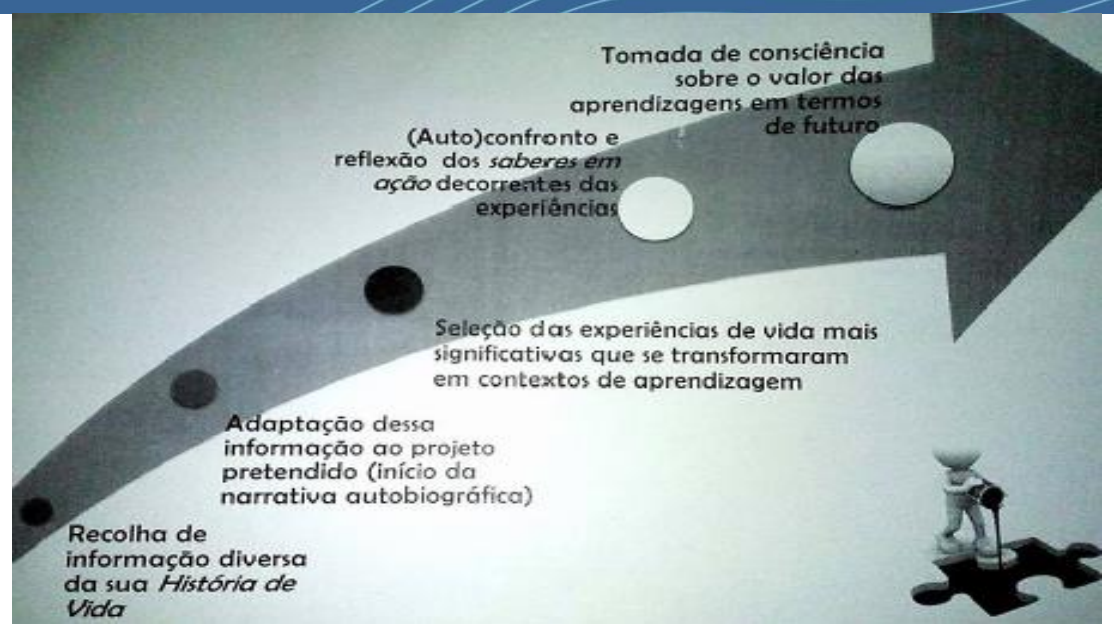

Fonte: ANQEP, 2017b, p.11

Tudo o que for incluído no PRA deve ser contextualizado e fazer sentido para conhecer melhor o candidato ou para reconhecer e validar as suas competências. Há partes da vida do candidato que não interessam para o processo, pois de acordo com a certificação ambicionada são privilegiados certos domínios, competências e saberes, mais restritos do que os adquiridos nos vários contextos de vida dos candidatos (OLIVEIRA PIRES, 2007).

Os PRA ficam armazenados digitalmente nos Centros Qualifica, apenas para acesso da equipa técnico-pedagógica responsável, existindo ainda alguns PRA em papel que quando termina o processo de RVCC, são devolvidos aos candidatos que o solicitarem, garantindo a confidencialidade da informação.

O PRA é um trabalho subjetivo que não pode esquecer a fidelidade, por vezes dúbia, da memória dos candidatos em relação aos factos e análises que vão fazendo. Assim, surge um dos problemas na avaliação de competências, pois o candidato não é avaliado quando as adquire mas sim a posteriori, por vezes, anos depois (CAVACO, 2007). Para além disto, os adultos desvalorizam ou desconhecem experiências que podem ter estado na base da aquisição de competências úteis para o processo de RVCC (CAVACO, 2007).

Este portefólio possibilita a validação das competências do candidato face ao referencial de competências-chave através do qual desenvolve o processo de RVCC - nível escolar básico ou secundário, profissional ou dupla certificação, sendo que em todas as áreas de competências-chave apresentadas na Figura 3, devem ser demonstradas competências.. 


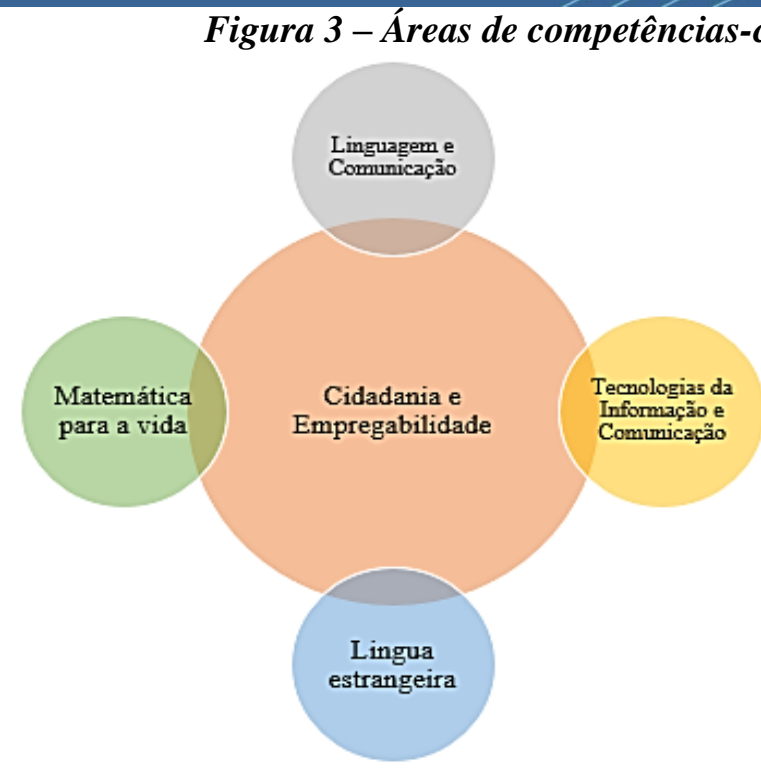

Nivel Básico

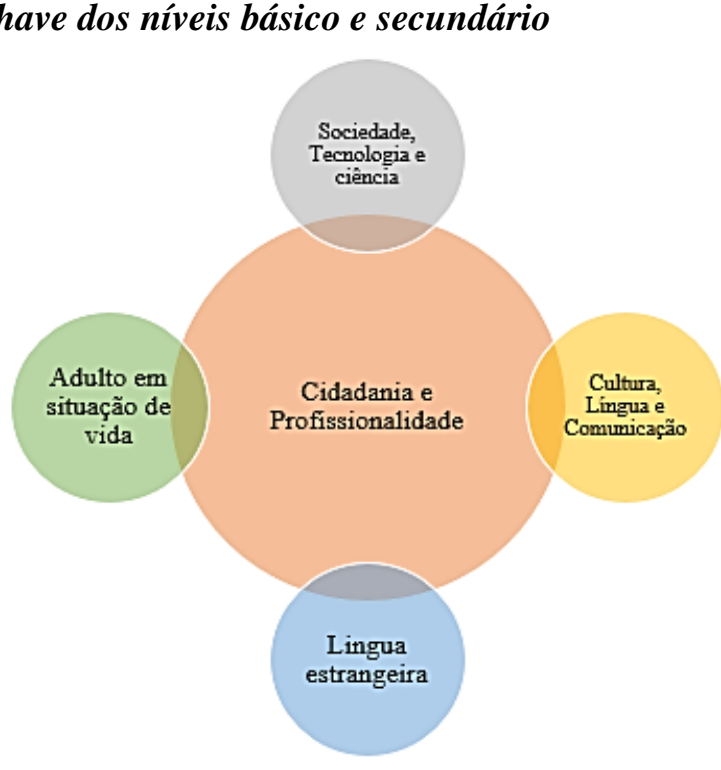

Nivel Secundário

Fonte: O autor (2019)

Para além do PRA, são imprescindíveis ao desenvolvimento e conclusão do processo de RVCC os seguintes documentos: Plano Individual de Carreira (PIC), o Plano Individual de Encaminhamento (PIE), o Plano Pessoal de Qualificações (PPQ) e os Referenciais de Competências-Chave do Catálogo Nacional de Qualificações (CNQ). A estes acrescem várias fichas como a de inscrição, a de diagnóstico (para formadores), a de análise do PRA e a de Avaliação. Todos os documentos são emitidos pelo Sistema de Informação e Gestão da Oferta Educativa (SIGO), exceto os Referenciais.

Como já afirmado anteriormente, os processos de RVCC são desenvolvidos por etapas, sendo elas a de Orientação ao longo da vida, de Encaminhamento, de Formação, de Reconhecimento e Validação de Competências e de Certificação das mesmas.

\subsection{Etapas}

\subsubsection{Orientação ao longo da vida}

Nesta etapa, os TORVCC tentam adequar os interesses e aptidões dos candidatos às oportunidades de aprendizagem, motivam-nos para a formação contínua, ajudam-nos a encontrar o seu percurso de qualificação e a identificar competências e aprendizagens adquiridas ao longo da vida (ORGANIZAÇÃO PARA A COOPERAÇÃO E 


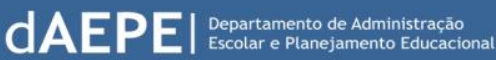

DESENVOLVIMENTO ECONÓMICO, 2005). Esta etapa divide-se em acolhimento, diagnóstico, informação e orientação.

O Acolhimento consiste no atendimento, inscrição e esclarecimento dos candidatos sobre a missão e o âmbito de intervenção dos Qualifica (ANQEP, 2017c).

O Diagnóstico compreende a recolha, com a ajuda do TORVCC, de informações relativas a "dados pessoais; motivações e expectativas; percurso de educação e formação; percurso profissional; ocupações de tempos livres e interesses; competências; entre outros" (ANQEP, 2017c, p. 11). Estas informações servem para analisar o perfil do candidato, podendo durar 1 a 6 sessões.

A Informação e Orientação permitem aos TORVCC, identificarem projetos individuais de educação e de formação profissional. A partir daí, disponibilizam informação sobre as ofertas de educação e de formação existentes no território de atuação do Qualifica onde estão inscritos e sobre as dinâmicas do mercado de trabalho, de modo a possibilitar a opção pela resposta que melhor se adeque ao candidato (PORTUGAL, 2016, IEFP, 2018). Nesta fase, que pode durar entre 1 a 8 sessões, deve-se elaborar o PIC $^{5}$ que apoia o candidato e o TORVCC na tomada de decisão sobre a resposta mais ajustada ao perfil do candidato.

A informação recolhida nesta primeira etapa tem como objetivo o Encaminhamento adequado e edicaz pelos TORVCC.

\subsubsection{Encaminhamento}

O Encaminhamento consiste na direção do candidato para um percurso de educação, de formação profissional ou de dupla certificação, segundo o acordado entre o Qualifica e o candidato, que fica formalizado num Contrato.

Nesta etapa, desenvolvida numa sessão, o TORVCC deve preencher o PIE que contém a modalidade de qualificação pretendida e a designação e a localização da entidade formadora que a irá promover (ANQEP, 2017c).

\subsubsection{Formação}

A Formação ocorre, geralmente, após o TORVCC ter monitorizado e identificado as competências do candidato, em consonância com o mesmo, através do PRA e do balanço de competências. Tem como finalidades "(re)aproximar ao contexto de aprendizagem formal, e

\footnotetext{
${ }^{5}$ Nele deve constar a definição de um projeto de carreira, onde se estabelecem metas e objetivos a alcançar; a fundamentação; a forma de o alcançar e os constrangimentos que podem surgir; estratégias de superação e o cronograma para a concretização do projeto (ANQEP, 2017c, p. 12).
} 
potencializar a possibilidade de obtenção de certificação total" (ANQEP, 2017b, p. 43), e é dada nas áreas em que o candidato demonstrou lacunas no PRA, tendo uma carga horária mínima obrigatória de 50 horas. Pode ocorrer numa fase inicial do processo ou durante o mesmo até à sessão de validação, e em caso de certificação parcial, de acordo com o prescrito no PPQ, também pode ser após a certificação. No caso de dupla certificação é necessário que o candidato frequente 100 horas de formação, geralmente 50 horas relativas à parte escolar e 50 horas relativas à parte profissional.

A formação pode ser à distância, nas instalações do Qualifica, em contexto de trabalho ou através de autoformação (IEFP, 2018). Pode ser complementar interna, organizada e promovida pela equipa do Qualifica que acompanha o processo, incidindo em uma ou mais UC. Ou pode ser complementar externa, ministrada por entidades formadoras do Serviço Nacional de Qualificações, se os candidatos demonstrarem lacunas numa determinada UC, através da frequência de Formação Modular em simultâneo com o processo de RVCC, em uma ou mais Unidades de Formação de Curta Duração (UFCD) que correspondam ou não, diretamente, às UC do referencial em avaliação (ANQEP, 2017d).

O formador para além de ensinar, avalia as competências evidenciadas no PRA, identificando-as e explorando-as juntamente com os candidatos. Ao longo da formação, apresenta tarefas aos candidatos orientando a sua resolução e explicitando alguns elementos teóricos fundamentais para a sua concretização (CAVACO, 2007).

\subsubsection{Reconhecimento e Validação de competências}

Esta é a etapa mais demorada do processo e abrange a identificação das competências desenvolvidas ao longo da vida do candidato, através da construção do PRA. Nesta etapa o TORVCC, deve apresentar e explicar os Referenciais de Competências-Chave ao candidato.

$\mathrm{O}$ adulto deve conseguir dar resposta a questões como "Qual foi o meu percurso de vida ao nível profissional, familiar, social e escolar/formação profissional? Que competências adquiri ao longo do percurso de vida? Onde as usei?", equacionando a questão "Porque sou o que sou?" (CAVACO, 2007, p. 24). Isto faz parte da abordagem autobiográfica que o processo de RVCC segue, sendo que o intuito não é avaliar o candidato como pessoa.

O Balanço de Competências é a metodologia base desta etapa e permite a exploração e monitorização das competências detidas pelos candidatos e a identificação e definição das competências onde deve incidir a formação complementar (ANQEP, 2017c). 
A Validação de competências compreende a autoavaliação do candidato e a heteroavaliação do TORVCC e dos formadores/professores envolvidos no processo, e fica formalizada numa reunião convocada e presidida pelo Coordenador/TORVCC do respetivo Qualifica onde se desenvolveu o processo de RVCC. Nesta reunião deve-se ter em conta que há regras específicas de avaliação para cada tipo de certificação efetuada (ANQEP, 2017c).

Quando o candidato não evidencia a totalidade das competências, adicionalmente ao PRA, o Formador deve recorrer a metodologias como a entrevista técnica individual, a aplicação de exercícios práticos a observar em contexto simulado e a observação direta em contexto de trabalho (IEFP, 2018).

\subsubsection{Certificação de Competências}

Reunidas as condições necessárias para a certificação de uma qualificação, o processo de RVCC culmina numa Sessão de Júri de Certificação de Competências validadas. Nesta sessão o candidato é apresentado a um Júri constituído, no caso de um processo de RVCC escolar, por um formador de cada área das competências-chave, que não tenha acompanhado o processo e o TORVCC que o geriu. Este dispõe de 25 horas para apoiar o candidato na preparação para a prova ajudando a escolher uma temática para a apresentação e explicando no que consiste a mesma (PORTUGAL, 2016). Pode existir ainda uma simulação da Prova de Aptidão Final para o candidato treinar.

Num processo de RVCC Profissional, o Júri é constituído por 2 formadores com qualificação técnica na área profissional visada e, pelo menos 5 anos de experiência profissional, o formador que acompanhou o processo do candidato, 1 representante das entidades empregadoras e 1 representante das associações sindicais dos setores de atividade económica da área. Na dupla certificação intervêm, separadamente, os júris dos 2 tipos de certificação já mencionados, primeiro o do Escolar e depois o do Profissional (PORTUGAL, 2016). Nesta sessão de Júri, a Prova de Aptidão Final feita pelo candidato deve consistir numa apresentação e exposição oral subordinada a uma temática integradora trabalhada no PRA. No caso da certificação profissional ou dupla, também deverá existir uma prova prática sobre a saída profissional pretendida.

Na prova prática, os candidatos trabalham um certo número de UC, segundo a ANQEP (cf. 2017c, 2017d), de acordo com o nível de certificação à qual se candidatam. Os elementos 
do Júri devem confirmar se os candidatos detêm as competências em avaliação e elaborar um conjunto de questões que permitam ao candidato refletir e emitir uma opinião (ANQEP, 2017d).

Na deliberação do Júri, o candidato pode obter Certificação Total que confere um Certificado de Qualificações e um Diploma de Nível 2 (Nível Básico) ou de Nível 4 (Nível Secundário) procedendo-se à definição do Plano de Desenvolvimento Pessoal do candidato. $\mathrm{Ou}$ Certificação Parcial, caso uma ou mais UC que integram a qualificação definida no encaminhamento não sejam certificadas. Isto confere um Certificado de Qualificações com todas as UC validadas no processo, passando-se à emissão do PPQ quando é necessário adquirir conhecimentos e competências profissionais (SIMÕES \& SILVA, 2008).

Por vezes o candidato não percorre todas as etapas do processo de RVCC, desistindo por motivos como a falta de tempo ou cansaço, a falta de autoestima ou de empatia com o TORVCC.

\section{Importância}

Estatisticamente, o processo de RVCC ajuda a aumentar as qualificações da população e a taxa de emprego.

Para além destas mudanças, os processos RVCC relançaram os debates acerca da obtenção de um nível de escolaridade, da aquisição de competências ao longo da vida e da forma de as certificar, ou seja, a questão da legitimidade. Estudos referenciam que possíveis candidatos aos processos de RVCC se mostram reticentes por duvidarem do reconhecimento socioprofissional das certificações concedidas (PAULA ALMEIDA, 2017).

Estes processos trazem a oportunidade de reconhecer e validar "o saber de experiência feito" causando uma mudança de paradigma (PIRES, 2002). Isto gera alguma controvérsia "pois não se entende como é que se pode reconhecer um saber e atribuir-lhe significado educativo, fora do contexto escolar e mais tarde equipará-lo a um grau académico" (MATIAS, 2012, p. 74), estando associado ao facilitismo. O processo de RVCC é assim um desafio à educação e formação ao longo da vida.

Em 2007, um estudo português dirigido pelo CIDEC - Centro Interdisciplinar de Estudos Económicos relativo à opinião dos candidatos sobre o processo de RVCC, concluiu que os maiores impactos se refletem na realização pessoal, na autoestima e na valorização dos 
candidatos por eles próprios e pela sociedade - reconhecimento. Outros impactos, que nem sempre se verificam são na progressão na carreira, na (re)construção do projeto profissional, na (re)inserção no mercado de trabalho e no aumento da motivação para procurar emprego e para prosseguir estudos (CIDEC, 2007). Este estudo considerou ainda que o RVCC é um estímulo para a aprendizagem ao longo da vida e um método compatível com a vida dos adultos que possibilita o crescimento pessoal, familiar e profissional, o aumento da integração dos adultos na sociedade e a diminuição do abandono escolar. Contudo, aponta-lhe algumas fraquezas como a falta de divulgação, instabilidade de algumas equipas técnico-pedagógicas, metas demasiado ambiciosas e uniformes não tendo em conta as especificidades de cada região e a insuficiência de recursos humanos para dar resposta ao número de processos e a toda a gestão administrativa a que estes obrigam (CIDEC, 2007).

Para além disto, o processo de RVCC aumenta o nível de participação em atividades de caráter cultural e social promovendo o desenvolvimento de uma sociedade mais inclusiva e com maior igualdade de oportunidades. Tem impacto a nível económico e social pois o aumento das qualificações contribui para "mais acesso à educação, emprego mais estável, melhores salários e saúde e mais elevados níveis de participação social e compromisso cívico" (PEREIRA, BORGES \& CASTRO, 2010, p. 79). E incute nos candidatos hábitos de escrita e leitura, pois a leitura e interpretação dos referenciais de competências-chave e a elaboração do PRA implicam a ativação de competências comunicativas, culturais, sociais, linguísticas e textuais (MATIAS, 2012).

Segundo a UNESCO, os contributos do processo de RVCC, para além dos já mencionados, são a redução da pobreza e o empoderamento dos marginalizados na sociedade (YANG, 2015). Para Soares, o processo de RVCC é "uma solução criativa, valorizadora, eficaz - em termos das pessoas que a ele recorrem e em termos da sociedade em que se inserem -, e muito pouco dispendiosa" (2007, p. 190). Rodrigues e Aragão e Lima de Oliveira (2011), acrescentam a estes impactos, o aumento da perceção das competências cognitivas, motivação, prudência na aprendizagem, reforço da capacidade de aprender, e aumento da satisfação com a vida devido ao alcance de objetivos de qualificação escolar/obtenção de carteira profissional.

Empresarialmente, os benefícios são ao nível da gestão de recursos humanos, ao proporcionar uma gestão interna das competências mais eficaz, e construir pontes para a mobilidade e evolução das carreiras dos colaboradores (PIRES, 2002). No entanto, há 
empresários que não consideram a certificação obtida através do processo de RVCC como relevante para o desempenho dos seus colaboradores (PAULA ALMEIDA, 2017).

Ao longo dos anos, o número de processos de RVCC tem aumentado, no entanto, os Centros Qualifica e o sistema de educação e formação profissional não se podem "deslumbrar" com estes dados, pois podem ser vistos como uma "máquina" de certificação. O estabelecimento de metas curriculares demasiado ambiciosas faz com que as equipas técnicopedagógicas que acompanham os processos de RVCC não dêem a devida atenção aos candidatos em cada etapa. Isto faz com que o processo seja menos apelativo para possíveis candidatos, levando-os a ponderar que somente confere certificados para valores estatísticos, não melhorando a sua situação face à educação, à formação e ao emprego.

\section{Conclusão}

A educação de adultos surgiu com os grandes mestres dos tempos antigos nas civilizações romana, helénica e indiana. Para além destas civilizações, também algumas religiões inspiraram a educação de adultos como o judaísmo, o islamismo e o cristianismo. Ao logo do tempo, a educação e formação de adultos passou a ter em consideração que se aprende permanentemente ao longo da vida, e que os adultos não aprendem da mesma forma que as crianças. Citando Hargreaves "o ensino deve ser uma carreira de primeira eleição, uma tarefa para adultos maduros, um compromisso a longo prazo, uma missão social e um emprego para a vida" (2003, p. 101).

A educação e formação de adultos como subsistema autónomo surgiu, em Portugal, apenas em 2001 com a criação dos Centros de RVCC, que em 2016 se tornaram os atuais Centros Qualifica. Estes Centros têm como objetivos melhorar a relevância e a qualidade da educação e da formação profissional, contribuindo para a competitividade nacional e para o aumento da empregabilidade, e assegurar as condições necessárias para que a população ativa possa reforçar e ver reconhecidas as suas qualificações e aprendizagens efetuadas ao longo da vida.

Não esquecendo a Sociedade do Conhecimento em que se vive, percebe-se, claramente, que o processo de RVCC vai ao encontro desta premissa. Baseia-se nas competências adquiridas pelas pessoas ao longo da sua vida, em contextos formais, não formais e informais, demonstradas num portefólio que permite o seu reconhecimento, certificação e validação de 


\section{REVISTA DE ADMINISTRAÇÃO EDUCACIONAL}

acordo com os Referenciais de Competências-Chave regulados pela ANQEP. Este é um processo bastante importante no sistema de educação e formação português, sendo considerado um fator decisivo para a promoção da educação/formação ao longo da vida (PIRES, 2002). Permite elevar as qualificações da população sem custos para os candidatos, aumentar a autoestima do candidato devido ao reconhecimento social e empresarial das suas competência e aumentar a taxa de emprego, comportando muitas outras vantagens a nível pessoal, social e profissional. Como todos os processos também comporta algumas "desvantagens" pois ainda existe bastante desconfiança face a este tipo de "atribuição de qualificações", no entanto as vantagens superam as desvantagens.

\section{Referências Bibliograficas}

AGÊNCIA NACIONAL PARA A QUALIFICAÇÃO E O ENSINO PROFISSIONAL. Jornadas Qualifica - RVCC escolar: metodologias e instrumentos. Lisboa: ANQEP, 2017b.

. Reconhecimento, validação e certificação de competências escolares (RVCC escolar): orientação metodológica. Lisboa: ANQEP, 2017c

Reconhecimento, validação e certificação de competências profissionais (RVCC profissional): orientação metodológica. Lisboa: ANQEP, 2017d

AMADO, J. \& FERREIRA, S. Documentos pessoais (e não pessoais). In: AMADO, J. (Coord.). Manual de Investigação Qualitativa em Educação. $2^{\text {a }}$ Ed. Coimbra: Imprensa da Universidade de Coimbra, 2014, p. 275-289.

BARROS, R. From lifelong education to lifelong learning: Discussion of some effects of today's neoliberal policies. European Journal for Research on the Education and Learning of Adults, Linköping, SE, v. 3, n. 2, p. 119-134, outubro, 2012. Disponível em <http://www.rela.ep.liu.se/issues/10.3384rela.2000-7426.201232/rela0071/rela0071.pdf>. Acesso em 25 abr.2018.

CAVACO, C. Reconhecimento, validação e certificação de competências: complexidade e novas actividades profissionais. Sísifo: Revista de Ciências da Educação, Lisboa, v. 2, p. 21-33, abril, 2007. Disponível em <http://repositorio.ul.pt/handle/10451/32072>. Acesso em: 25 abr.2018.

CENTRO INTERDISCIPLINAR DE ESTUDOS ECONÓMICOS. O impacto do reconhecimento e certificação de competências adquiridas ao longo da vida: actualização e aperfeiçoamento. Lisboa: Direção-Geral de Formação Vocacional, 2007, 96 p. Disponível em <http://www.anqep.gov.pt/aaaDefault.aspx ?back $=1 \& \mathrm{f}=1 \& l w s=1 \& \mathrm{mcna}=0 \& \operatorname{lnc}=6215 \mathrm{AAAAA}$ 
AAAAAAAAAAAAAA\&codigono=57656163AAAAAAAAAAAAAAAA $>$. Acesso em: 16 abr.2018.

HARGREAVES, A. O ensino na sociedade do conhecimento - a educação na era da insegurança. Porto Editora: Porto, 2003, 230 p.

INSTITUTO DO EMPREGO E FORMAÇÃO PROFISSIONAL. Centros Qualifica - guia organizativo para a rede de centros do IEFP, I.P. Lisboa: IEFP, 2018.

LIMA DE OLIVEIRA, A. Motivar as pessoas adultas para aprender ao longo da vida. In: CONSELHO NACIONAL DE EDUCAÇÃO (Org.). Estado da Educação 2016. Lisboa: CNE, 2017, p. 328-339. Disponível em $\langle$ http://www.cnedu.pt/content/edicoes/estado_da_educacao/CNE-EE2016_web_final.pdf〉. Acesso em: 29 mar. 2018.

MATIAS, A.M.P. O impacto do processo de RVCC na proficiência linguística em Prosa das competências linguísticas às aplicações didáticas. Tese (Doutoramento em Letras) Faculdade de Artes e Letras, Universidade da Beira Interior, Covilhã, 2012, 322 p. Disponível em 〈https://ubibliorum.ubi.pt/bitstream/10400.6/1838/1/Tese.pdf>. Acesso em: 29 mar. 2018.

NOGUEIRA, S.M. A andragogia: que contributos para a prática educativa? Revista Linhas, Florianópolis, SC, v. 5, n. 2, p. 333-356, agosto, 2004. Disponível em <http://www.revistas.udesc.br/index.php/linhas/article/view/1226/1039>. Acesso em: 07 jan. 2018.

OLIVEIRA PIRES, A.L. Reconhecimento e Validação das Aprendizagens Experienciais: Uma problemática educativa. Sísifo: Revista de Ciências da Educação, Lisboa, v. 2, p. 5-20, abril, 2007. Disponível em <https://comum.rcaap.pt/bitstream/10400.26/21912/1/Reconhecimento\%20e\%20valida\%C3\%A $\%$ C3\%A3o\%20das\%20aprendizagens\%20experienciais\%20-\%20pp.\%205-20.pdf $>$. Acesso em: 20 mar. 2018.

ORGANIZAÇÃO PARA A COOPERAÇÃO E DESENVOLVIMENTO ECONÓMICO. Orientação escolar e profissional - guia para decisores. 2005, 96 p. Disponível em $<$ http://iccdpp.org/wpcontent/uploads/2014/03/CG-HB-PT Orient.Escolar_guia_para_decisores.pdf>. Acesso em: 25 abr. 2018.

PAULA ALMEIDA, A. Os processos de reconhecimento, validação e certificação de competências profissionais: reflexão sobre uma experiência. Revista Portuguesa de Pedagogia, Coimbra, v. 50, n. 1, p. 79-95, janeiro, 2017.

PEREIRA, M., BORGES, Z. \& CASTRO, J.M. (2010). O impacto do processo RVCC na aprendizagem ao longo da vida. In: LEITE, A., CASTRO, J.M. \& COIMBRA, J.L. (Org.). Os novos profissionais da educação e formação para o trabalho: desafios e exigências da aprendizagem ao longo da vida. Atas do XII Congresso Internacional de Formação para o Trabalho Norte de Portugal/Galiza. Guimarães, 2010, p. 73-78. Disponível em 
$\langle$ https://sigarra.up.pt/fpceup/pt/pub_geral.pub_view?pi_pub_base_id=85225>. Acesso em: 25 jan. 2018.

PINEAU, G. Temporalités en formation: vers de nouveaux synchroniseurs. Paris: Anthropos, 2000,214 p.

PIRES, A.L.O. Educação e formação ao longo da vida: análise crítica dos sistemas e dispositivos de reconhecimento e validação de aprendizagens e de competências. Dissertação (Doutoramento em Ciências da Educação) - Faculdade de Ciências e Tecnologia, Universidade Nova de Lisboa, Lisboa, 2002, 646 p. Disponível em 〈https://run.unl.pt/bitstream/10362/1004/1/pires_2002.pdf〉. Acesso em: 25 jan. 2018.

PORTUGAL. DECRETO-LEI N. . 387/99, DE 28 DE SETEMBRO DE 1999. Criação da ANEFA. Lisboa: Ministério da Educação, jan 2018. Disponível em <https://dre.pt/application/file/a/668070>. Acesso em: 10 fev. 2018.

. DECRETO-LEI N. ${ }^{\circ}$ 396/2007 de 31 de dezembro. Estabelece o regime jurídico do Sistema Nacional de Qualificações e define as estruturas que regulam o seu financiamento. Lisboa: Ministério do Trabalho e da Solidariedade Social, jan 2018. Disponível em 〈http://www.catalogo.anqep.gov.pt/boDocumentos/getDocumentos/155>. Acesso em: $10 \mathrm{fev}$. 2018.

. PORTARIA N. ${ }^{\circ} 1082-\mathrm{A} / 2001$, DE 5 DE SETEMBRO. Cria uma rede nacional de centros de reconhecimento, validação e certificação de competências (centros RVCC). Lisboa: Ministério da Educação e do Trabalho e da Solidariedade, abril 2018. Disponível em $<$ https://dre.pt/application/file/a/307524>. Acesso em: 10 fev. 2018.

. PORTARIA N. ${ }^{\circ}$ 232/2016, DE 29 DE AGOSTO. Procede à regulação da criação e do regime de organização e funcionamento dos Centros Qualifica. Lisboa: Ministérios da Educação e Trabalho, Solidariedade e Segurança Social, abril 2018. Disponível em <https://dre.pt/application/file/a/75217575>. Acesso em: 11 fev. 2018.

RODRIGUES E ARAGÃO, R.S.C. \& LIMA DE OLIVEIRA, A. A capacidade de aprendizagem ao longo da vida e o bem-estar dos adultos em processo de RVCC de nível secundário. In ALCOFORADO. L.; FERREIRA, J.A.G.; FERREIRA, A.G.; LIMA, M.P.; VIEIRA, C.; OLIVEIRA, A.L.; FERREIRA, S.M. (Org.). Educação e formação de adultos: políticas, práticas e investigação. Coimbra: Imprensa da Universidade de Coimbra, 2011, p. 113-130.

SIMÕES, M. F. \& SILVA, M. P. A operacionalização de processos de reconhecimento, validação e certificação de competências profissionais - guia de apoio. Lisboa: ANQ, 2008 Disponível em $<$ http://www.anqep.gov.pt/pagina. aspx $? \mathrm{f}=1 \& l \mathrm{ws}=1 \& \mathrm{mcna}=0 \& \operatorname{lnc}=$ AAAAAAAAAAAAAAA AAAAAAAA \&parceiroid $=0 \&$ codigoms $=0 \&$ codigono $=6370$ AAAAAAAAAAAAAAAAAAAA >. Acesso em: 13 jan. 2018.

SOARES, M.P. Algumas reflexões em torno do processo de RVCC. In: CONSELHO 
NACIONAL DE EDUCAÇÃO. Aprendizagem ao Longo da Vida no Debate Nacional sobre Educação. Lisboa: Conselho Nacional de Educação, 2007, p. 189-192. Disponível em $<$ http://www.cnedu.pt/pt/publicacoes/estudos-e-relatorios/outros/789-aprendizagemao-longo-da vida-no-debate-nacional-sobre-educacao\#noopener\%20noreferrer/8/>. Acesso em: 11 fev. 2018.

STIGLITZ, J.E. \& GREENWALD, B.C. La creácion de una sociedad del aprendizaje: Uma nueva aproximación al crecimiento, el desarrollo y el progreso social. Madrid: La esfera de los libros, 2016, $680 \mathrm{p}$.

YANG, J. Recognition, validation and accreditation of non-formal and informal learning in UNESCO Member States. Hamburgo: UNESCO Institute for Lifelong Learning, 2015, 68 p. Disponível em 〈http://unesdoc.unesco.org/images/0023/002326/232656e.pdf 〉. Acesso em: 13 jan. 2018. 